\title{
Comparative Evaluation of the Adsorption of Chromium (VI) by Modified and Unmodified Mangrove Leaf Sorbents
}

\author{
NDUKA, EN; COOKEY, GA; *IBOROMA, SD \\ Department of Chemistry, Rivers State University, Port Harcourt, Nigeria \\ *Corresponding Author Email: daopuye.iboroma1@ust.edu.ng
}

\begin{abstract}
The adsorption capacity of modified (MML) and unmodified (UML) mangrove leaves sorbents on chromium (VI) was analyzed in terms of $\mathrm{pH}$, adsorbent doze, chromium (VI) concentration and contact time using batch adsorption technique. Results obtained showed greater chromium (VI) adsorption on MML than UML. Adsorption capacity diagrams described for MML were higher than those of UML. The adsorption was influenced by low medium $\mathrm{pH}$, low adsorbent dosage, high chromium (VI) concentration and long contact time. Adsorptive capacity decreased from 15.9 - 14.19mgg ${ }^{-1}$, for MML and 13.59 - 12.19 $\mathrm{mgg}^{-1}$, for UML and from 74.99 - 9.59mgg ${ }^{-1}$, for MML and 44.89 - 5.79mgg 1 , for UML as $\mathrm{pH}$ and adsorbent dosage were increased from (2 to 8) and (0.25 to 2g); but increased from 5.09-46.19mgg ${ }^{1}$, for MML and $1.89-25.59 \mathrm{mgg}^{-1}$, for UML and from $26609.0-38719.0 \mathrm{mgg}^{-1}$, for MML and $28869.0-35089.0 \mathrm{mgg}^{-1}$, for UML as concentration of chromium (VI) and time of contact increased from (10 to 100ppm) and (30 to $240 \mathrm{minutes}$ ), respectively. Isotherm studies reveal that experimental data for MML and UML fitted on Freundlich adsorption $\left(\mathrm{R}^{2} \geq\right.$ $0.93)$. Kinetic data analyses, with $\left(\mathrm{R}^{2} \geq 0.962\right)$ on pseudo-second order model, suggest chemisorption process for both sorbents. These results suggest the extract of mangrove leaves material after acid modification can be used as biosorbent for chromium (VI) removal in aqueous solution.
\end{abstract}

\section{DOI: https://dx.doi.org/10.4314/jasem.v23i6.5}

Copyright: Copyright $\left({ }^{\circ} 2019\right.$ Nduka et al. This is an open access article distributed under the Creative Commons Attribution License (CCL), which permits unrestricted use, distribution, and reproduction in any medium, provided the original work is properly cited.

Dates: Received: 13 May 2019; Revised: 19 June 2019; Accepted 07 June 2019

Keywords: Adsorption, Mangrove Leaf, Chromium (VI), Freundlich, Langmuir

Chromium is one of the most common heavy metal pollutants released into the environment during chrome-plating, leather tanning, wood preservation and mining operations (Nordiana et al., 2013). It has multiple oxidation numbers ranging from -2 to +6 . The +3 and +6 states are more prevalent but the latter is more soluble and toxic in aqueous environment (Sathish, et al., 2015). Chromium has been reported to be carcinogenic and can cause nasal, kidney and liver damage, asthma, ulcer and skin irritation when found above the tolerance level (Stout et al., 2009). Many researchers (Nameni et al., 2008; Olayinka et al., 2009; Abdullahi et al., 2012; Ofudje et al., 2016; Timbo et al., 2017) have focused on adsorption techniques, especially the use of agricultural waste materials for the removal of heavy metals from aqueous solutions. Studies on the use of modified and unmodified plant materials have been reported (Rozaini et al., 2010; Ofudje et al., 2014; Sathish et al., 2015).

Mangrove (Rhizophora mangle), a marine coastal plant, is abundantly found in the southern region of Nigeria. The stem of the plant is harvested for use as fire wood and for making charcoal by the inhabitants of the local communities while the leaves and roots are left as wastes. Conversion of these to valuable adsorbents would not only be economical but help reduce the waste disposal problems. According to Vazqueze et al. (2002) and Sathish, et al. (2015) these leaves contain polyphenolic compounds which under appropriate conditions are capable of adsorbing metal ion from solutions (sathish et al., 2015). In this work, the adsorption efficiencies of modified (MML) and unmodified (UML) leaves extracts sorbents in taking up chromium (VI) from aqueous solution was investigated by batch adsorption method. The objective of this paper was to evaluate and report the adsorption capacities of modified and unmodified mangrove leaf sorbents.

Materials and Methods: Analytical grade chemicals (potassium dichromate, sodium hydroxide, hydrochloric acid, sulfuric acid, sodium bicarbonate and nitric acid) were used without further purification. Other materials used were pocket size HANNA pH Meter (model H196107), phenonm world SEM-PRO (model X800-07334), Atomic Absorption Spectrophotometer (Agilent MP-AES 42100), mechanical grinder, $500 \mu m$ test sieve and Stuart orbital shaker.

Sample Preparation: Mangrove (Rhizophora) leaves were collected from swamp forest near Bakana, a 
riverine community in Degema Local Government Area of Rivers State, Nigeria. The leaves were thoroughly washed with deionized water to remove dirt, soil and other soluble particles, sun-dried for 5 days, crushed with mechanical grinder to obtain dry powder and then sieved using test sieve of $500 \mu \mathrm{m}$ particle size. Modification was done according to the method described by Nordiana et al., 2013. $30 \mathrm{~g}$ of the desired particle size $(500 \mu \mathrm{m})$ was treated with $50 \mathrm{ml}$ of $0.5 \mathrm{M}$ Sulfuric acid solution and kept in an oven for $24 \mathrm{hrs}$, then soaked in de-ionized water until the $\mathrm{pH}$ of the solution stabilized. $50 \mathrm{ml}$ of $0.5 \mathrm{M}$ sodium bicarbonate was added to the solution. After $1 \mathrm{hr}$, it was washed with de-ionized water until all residual acid was finally removed. The sample was oven dried for 5 hrs at $110^{\circ} \mathrm{C}$ until constant weight, then cooled and stored in a tightly covered container for further studies. Stock solution (1000ppm) of chromium (VI) was prepared by dissolving $2.828 \mathrm{~g}$ of potassium dichromate $\left(\mathrm{K}_{2} \mathrm{Cr}_{2} \mathrm{O}_{7}\right)$ in 1 liter of deionized water. Working solutions (10ppm, 20ppm, 40ppm, 60ppm and $100 \mathrm{ppm}$ ) were prepared from the stock by serial dilution. Surface morphology of the samples at the desired particle size was analyzed using Scanning Electron Microscope.

\section{METHODS AND METHODS}

Batch Adsorption Experiment: For both the modified and unmodified mangrove leaves sorbents, the effect of variations in $\mathrm{pH}(2-9)$, adsorbent doze $(0.25-2 \mathrm{~g})$ and chromium (VI) concentrations (10 - 100ppm) on the adsorption of chromium (VI) were carried out. The contact time was varied at 30 minutes intervals between 30 and 240 minutes, by determining residual chromium (VI) at the predetermined time intervals. Adjustment of $\mathrm{pH}$ was actualized by adding aqueous solutions of $0.1 \mathrm{M} \mathrm{HCl}$ or $0.1 \mathrm{M} \mathrm{NaOH}$. In each of these experiments, $20 \mathrm{ml}$ portion of chromium (VI) solution was measured and the resulting mixture equilibrated on an orbital shaker set at a speed of $150 \mathrm{rpm}$. The content of each beaker was filtered into a conical flask through Whatman No. 1 filter paper and the residual chromium (VI) concentration in the filtrate determined using AAS.

Adsorption Isotherm: Adsorption isotherm studies were carried out with initial concentrations of 10, 20, 40,60 and $100 \mathrm{ppm}$ at $\mathrm{pH}$ of 2 using $0.2 \mathrm{~g}$ of the adsorbent. Langmuir and Freundlich isotherm models were employed to interpret the adsorption process (equations 1 and 2 respectively).

$$
\begin{aligned}
& \frac{C_{e}}{q_{e}}=\frac{K_{l}}{q_{\max }}+\frac{1}{q_{\max }} \mathrm{C}_{\mathrm{e}} \\
& \log q_{e}=\log K_{f}+\frac{1}{n} \log C_{e}
\end{aligned}
$$

where $\mathrm{q}_{\max }$ is the maximum adsorption at monolayer $(\mathrm{mg} / \mathrm{g}), \mathrm{C}_{\mathrm{e}}$ is the equilibrium concentration of the adsorbate ion in solution, $\mathrm{q}_{\mathrm{e}}$ is the amount of ion adsorbed per unit weight of the adsorbent, $\mathrm{K}_{\mathrm{L}}$ is the Langmuir constant related to the affinity of binding sites, $\mathrm{K}_{\mathrm{f}}$ and $\mathrm{n}$ are called freundlich constants. $K_{f}$ defines the relative adsorption capacity while $n$ indicates the intensity of the adsorption.

The percentage chromium (VI) removed by mangrove leaves was evaluated from the difference between the initial $\left(\mathrm{C}_{\mathrm{o}}\right)$ and final $\left(\mathrm{C}_{\mathrm{f}}\right)$ concentrations as shown in equation 3. The amount of Chromium (VI) ion adsorbed was calculated using equation 4 .

$$
\begin{aligned}
& \% \text { Removal }=\frac{\left(C_{0}-C_{f}\right) 100}{C_{o}} \\
& q_{e}=\frac{\left(C_{o}-C_{f}\right) V}{m}
\end{aligned}
$$

Where $q_{e}$ is the equilibrium adsorption capacity $(\mathrm{mg} / \mathrm{g}), \quad C_{0}$ and $C_{\mathrm{f}}$ are the initial and final concentrations of chromium (VI) $(\mathrm{mg} / \mathrm{l}), \mathrm{V}$ is the volume of solution (l) and $\mathrm{m}$ is the mass of the adsorbent used (g).

Kinetic Studies: To investigate the kinetic properties of the adsorption, $0.2 \mathrm{~g}$ of the adsorbent was added to $20 \mathrm{ml}$ of $60 \mathrm{ppm}$ chromium (VI) solution and agitated for time intervals of 30,60, 90, 120, 150, 180, 210 and 240mins. The kinetics process was analyzed using the Pseudo-first order (equation 5) and pseudo-second order (equation 6) adsorption models by Lagergren (Ngugi. 2015).

$$
\begin{aligned}
& \log \left(q_{e}-q_{t}\right)=\log q_{e}-\left(\frac{K_{1}}{2.303}\right) t \\
& \frac{t}{q_{t}}=\frac{1}{K_{2} q_{e}^{2}}+\frac{1}{q_{e}} t
\end{aligned}
$$

In equations 5 and $6, \mathrm{q}_{\mathrm{e}}$ and $\mathrm{q}_{\mathrm{t}}$ represent the amount of chromium (VI) adsorbed at equilibrium and at a given time, t. $K_{1}$ and $K_{2}$ are the rate constants of the pseudofirst order and pseudo-second order adsorption processes, respectively.

\section{RESULTS AND DISCUSSION}

Surface Morphology: Images of modified and unmodified mangrove leaves samples were taken so as to observe possible changes on the surface if any. The SEM micrographs are presented in Figure 1. Both images were taken at $200 \mu \mathrm{m}$. Figure $1 \mathrm{~A}$ appears to be more porous and have wider surface area than UML (Figure 1B). Thus, MML has wider surface feasibility to adsorb chromium (VI) ions than UML. 


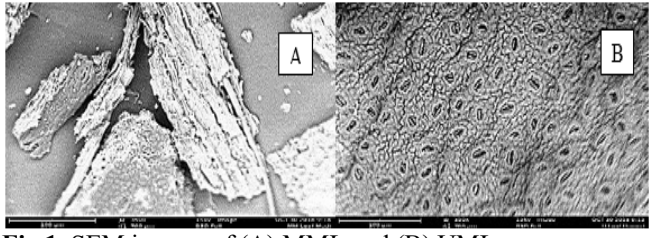

Fig 1. SEM images of (A) MML and (B) UML.

Effect of $p H$ : The adsorption capacities of $0.2 \mathrm{~g}$ MML and UML as a function of $\mathrm{pH}$ are presented in Fig. 2. The results show that the adsorption of chromium (VI) by both MML and UML decreased with the $\mathrm{pH}$ of the medium. Similar observation has also been made elsewhere (Sathish, et al., 2015). High adsorption capacity at low $\mathrm{pH}$ was attributed to strong electrostatic attraction between the adsorbent surface and the adsorbate. Adsorption of ions by biomaterials depends largely on the presence of active sites, nature of ion and $\mathrm{pH}$ of the medium under consideration. It is generally known that in low $\mathrm{pH}$, the adsorbent surface become positive while in alkaline medium (high $\mathrm{pH}$ ), adsorbent surface becomes negative. Chromium (VI), the hexavalent chromium ion, exists predominately in solution and in acidic medium as chromate ion $\left(\mathrm{HCrO}_{4}^{-}\right)$and thus possesses an anionic atmosphere which is negative (Olayinka et al., 2009) and so was adsorbed more in acidic medium by electrostatic attraction on the adsorbent surface. At higher solution $\mathrm{pH}$, electrostatic repulsion reduced chromium (VI) adsorption, thus adsorption capacity decreased.

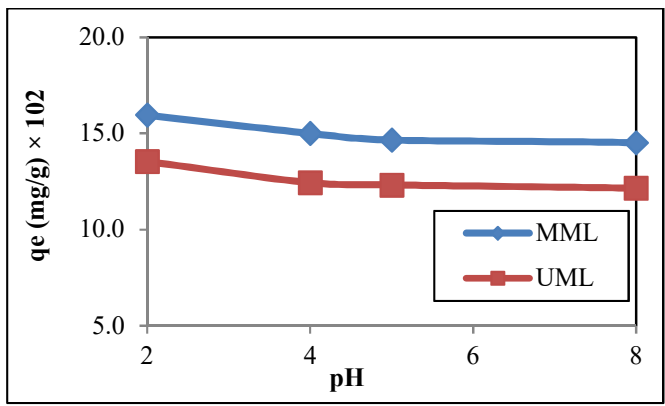

Fig 2: Plots of equilibrium adsorbent capacity, $\mathrm{q}_{\mathrm{e}}(\mathrm{mg} / \mathrm{g})$ as a function of solution $\mathrm{pH}$ for the adsorption capacity $\mathrm{q}_{\mathrm{e}}(\mathrm{mg} / \mathrm{g})$ as a function of Solution $\mathrm{pH}$ for the adsorption of Chromium (VI) by Mangrove leaves.

Effect of Adsorbent Doze: Figure 3 shows the inverse relationship between the adsorption capacities of modified and unmodified mangrove leaves and adsorbent doze. Similar observation has been made by Sathish, et al., (2015). The researchers did not provide reasonable explanation for the inverse relationship. It is known that increase in adsorbent doze results in larger surface area and more active sites for adsorption. Thus increase in adsorption capacity with dosage was expected. The decrease in adsorption capacity observed in this study is possibly due to increasing unsaturation caused by overcrowding of particles as the adsorbent doze increased.

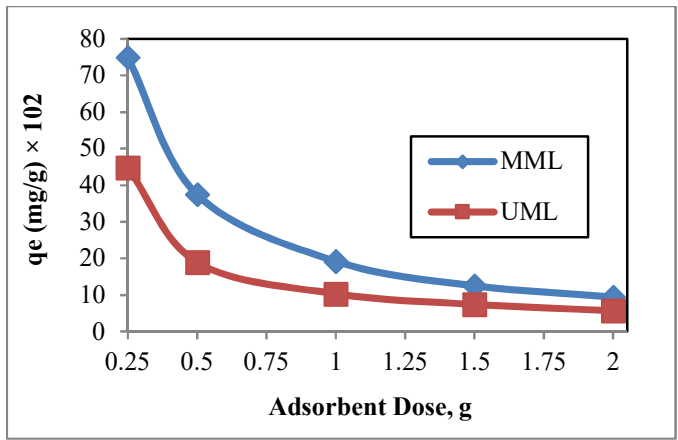

Fig 3: The adsorption capacity, $\mathrm{q}_{\mathrm{e}}(\mathrm{mg} / \mathrm{g})$ as a function of adsorbent doze (g) for 100ppm solution of chromium (VI)

Effect of Chromium (VI) ion Concentration: The adsorption capacities of modified and unmodified mangrove leaves on chromium (VI) are presented in Figure 4. The results indicate that the adsorption of chromium (VI) ion by MML and UML is directly proportional to the concentration of chromium (VI) ion. It is also observed that the adsorption capacity of MML was greater than that of UML. The increase in adsorption capacity observed can be attributed to the fact that the binding site was not saturated and so could probably bind more chromium (VI) if a higher initial concentration was used. Figure 4 reveals increase in adsorption capacity with concentration of the adsorbate with larger values of qe for MML than UML. This agrees with the SEM surface analysis (Figure 1) that indicates that MML has wider surface feasibility and more binding sites than UML.

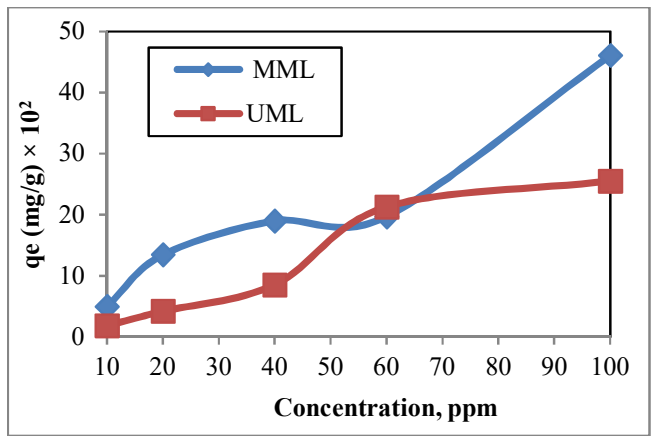

Fig 4: plot of Adsorption capacity of Mangrove leaves as a function of initial Chromium (VI) concentration $[\mathrm{pH}=2$, adsorbent doze $=$ $0.25 \mathrm{~g}]$

Effect of Contact Time: Adsorption capacities of MML and UML are displayed as a function of time of contact (Figure 5). The results (Figure 5) indicate that the adsorption capacity of both MML and UML increased with increase in contact time even after the 
attainment of equilibrium at 210 minutes, from 2660 to $3991 \mathrm{mg} / \mathrm{g}$, for MML and from 2886 to $3775 \mathrm{mg} / \mathrm{g}$, for UML. The increase may be due to long time of contact and also the availability of the vacant binding site on the adsorbents. The results suggest that the equilibrium time is dependent on the nature of the adsorbent. The higher values of qe obtained for MML than UML supports the results of Figure 4.

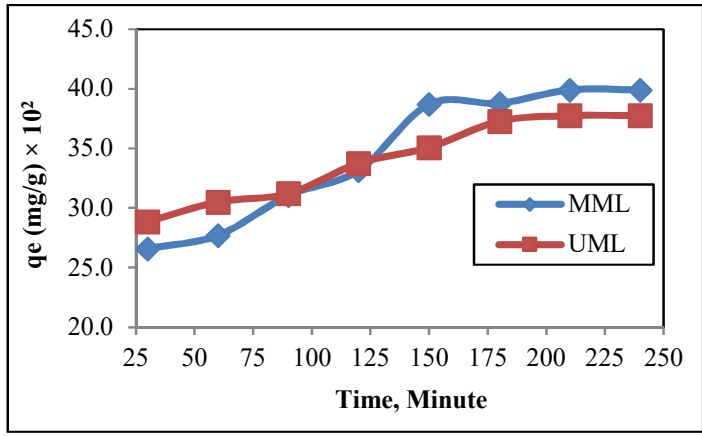

Fig 5: Variation of adsorption capacity of mangrove leaves on chromium (VI) as a function of time (minutes) $[\mathrm{pH}=2$, adsorbent doze $=0.25 \mathrm{~g}$, chromium $(\mathrm{VI})$ conc. $=100 \mathrm{ppm}]$

Adsorption Isotherm: Adsorption isotherm describes the equilibrium relationship between the adsorbate in the solution and the adsorbate on the adsorbent at constant temperature (Ali Riza et al., 2007). Models such as those of Langmuir (equation 1) and Freundlich (equation 2) are widely employed to describe experimental sorption data (Cookey et al., 2018). Langmuir parameters $\left(\mathrm{q}_{\max }\right.$ and $\left.\mathrm{K}_{1}\right)$ were calculated from the slope and intercept of the linear plot of $\mathrm{C}_{\mathrm{e}} / \mathrm{q}_{\mathrm{e}}$ versus $\mathrm{Ce}$ as depicted in equation 1. Similarly, Freundlich parameters ( $\mathrm{n}$, and $\mathrm{K}_{\mathrm{f}}$ ) were obtained from the slope and intercept of the linear plot of $\log \mathrm{q}_{\mathrm{e}}$ versus $\log C_{e}$ (equation 4). Their application is based on best-fit correlation coefficient $\left(\mathrm{R}^{2}\right)$ values. Good $\mathrm{R}^{2}$ values of 0.96 , for MML and 0.93 , for UML, indicate that the isotherm data contained in Table 1 are in conformity with Freundlich model, suggesting heterogeneous adsorption on surfaces of MML and UML. Favourable adsorption process occurs if $\mathrm{n}$ lies between 1 and 10 (Timbo, et al., 2017). Hence, with $\mathrm{n}$ value of 1.116 , for MML and 0.63, for UML, the results indicate that adsorption of chromium (VI) was more favoured on the surface of MML than UML. As may be seen, poor $\mathrm{R}^{2}$ values ( 0.38 and 0.76$)$ and other Langmuir parameters in Table 1 indicate nonconformity with the model.

Adsorption Kinetics: Kinetic parameters for the adsorption of chromium (VI) from aqueous solution were studied using the pseudo first (Equation 5) and second order (Equation 6) models. The Pseudo first order kinetic parameters were calculated by plotting graph of $\log \left(q_{e}-q_{t}\right)$ versus $t$ (time). The values of Pseudo-second order rate constant $\mathrm{k}_{2}$ and equilibrium adsorption capacity $\mathrm{q}_{\mathrm{e}}$ were calculated from the intercept and slope of a plot of $t / q_{t}$ versus $t$. These parameters have been evaluated for MML and UML and compared in Table 2. With pseudo-second order $\mathrm{q}_{\mathrm{e}}$ and $\mathrm{K}_{2}$ values of $5000 \mathrm{mg} / \mathrm{g}$ and $6.66 \times 10^{-}$ ${ }^{6} \mathrm{~g} / \mathrm{mg} / \mathrm{minute}$ computed for MML, and $3333 \mathrm{mg} / \mathrm{g}$ and $3.103 \times 10^{-5} \mathrm{~g} / \mathrm{mg} / \mathrm{minute}$ for UML, the results suggest that adsorption of chromium (VI) on the biomass occurred by chemical means and MML was a better adsorbent than UML. This is also in conformity with the $\mathrm{R}^{2}$ values of 0.9959 , for MML and 0.9623 , for UML. Table 2 also indicates good fit $\left(\mathrm{R}^{2}=0.94\right)$ for UML in the pseudo-first order model. However, the evaluated $\mathrm{q}_{\mathrm{e}}$ and $\mathrm{K}_{1}$ values $(1321 \mathrm{mg} / \mathrm{g}$ and 0.0099$)$ are relatively low.

Table 1: Isotherm Parameters for the adsorption of Chromium (VI) on MML and UML surfaces

\begin{tabular}{lllllll}
\hline & \multicolumn{3}{c}{ Langmuir } & \multicolumn{3}{c}{ Freundlich } \\
\hline & $\mathbf{K}_{\mathbf{L}}(\mathbf{l} / \mathbf{m g})$ & $\mathbf{Q}_{\max }(\mathbf{m g} / \mathbf{g})$ & $\mathbf{R}^{\mathbf{2}}$ & $\mathbf{K}_{\mathbf{f}} \mathbf{( m g / \mathbf { g } )}$ & $\mathbf{n}$ & $\mathbf{R}^{\mathbf{2}}$ \\
\hline MML & 178.89 & 1111 & 0.383 & 74.67 & 1.116 & 0.9627 \\
$\mathbf{U M L}$ & -70.00 & -1250 & 0.761 & 5.131 & 0.630 & 0.931 \\
\hline
\end{tabular}

Table 2: Kinetic Parameters of the adsorption of Chromium (VI) on MML and UML surfaces

\begin{tabular}{|c|c|c|c|c|c|c|}
\hline & \multicolumn{3}{|c|}{ Pseudo-first order } & \multicolumn{3}{|c|}{ Pseudo-Second order } \\
\hline & $q_{\mathrm{e}}(\mathrm{mg} / \mathrm{g})$ & $K_{1}\left(\operatorname{mins}^{-1}\right)$ & $\mathbf{R}^{2}$ & $q_{\mathrm{e}}(\mathrm{mg} / \mathrm{g})$ & $\mathrm{K}_{2}(\mathrm{~g} / \mathrm{mg} / \mathrm{mins})$ & $\mathbf{R}^{2}$ \\
\hline MML & 3286 & -0.0179 & 0.7563 & 5000 & $6.66 \times 10^{-6}$ & 0.9959 \\
\hline UML & 1321 & 0.0099 & 0.94 & 3333 & $3.103 \times 10^{-5}$ & 0.9623 \\
\hline
\end{tabular}

Conclusion: This study has compared the adsorption of chromium (VI) on modified and unmodified mangrove leaves sorbents in aqueous medium as functions of $\mathrm{pH}$, adsorbent doze, initial concentration of chromium (VI) and contact time in aqueous medium using batch adsorption technique. It was found that
MML exhibited higher adsorption capacity than UML. The adsorption was found to be more effective at low $\mathrm{pH}$ and adsorbent dosage, high chromium (VI) concentration and in longer contact time. Isotherm data analyses suggest heterogeneous adsorption for both adsorbents. The adsorption process is chemical in 
nature, according to kinetic studies. The overall results indicate that mangrove leaves, from an abundantly available plant, have great potential to adsorb chromium (VI) from aqueous solution.

\section{REFERENCES}

Abdullahi, BS; Aliyu, S; Ukuwa, S (2012). Biosorption of Chromium (vi) from solution by Corn cob Powder. Intern. J. Environ. Bioenergetics, 4: 131 - 140

Ali-Riza, D; Yalcin, G; Nusret, K; Elcin, G (2007). Comparison of activated carbon and bottom ash for removal of reactive dye from aqueous solution. Bioresource Technology, 98: 834 - 839

Cookey, GA; Tambari, BL; Iboroma, DS (2018). Evaluation of the corrosion inhibition potentials of green-tip forest lily (Clivia nobilis) leaves extract on mild steel in acid media. J. Appl. Sci. Environ. Manage. 22: 90 - 94

Nameni, M; Alavi, MR; Arami, M (2008). Adsorption of hexavalent Chromium from Aqueous solution by Wheat bran. Intern. J. Environ. Sci. \& technol., 15: $161-168$.

Nordiana, S; Mohmed, T; Nor, A; Mohd, Y (2013). Chromium (vi) removal from $\mathrm{K}_{2} \mathrm{Cr}_{2} \mathrm{O}_{7}$ solution using charcoal modified with oxidizing agents. Intern. J. Environ. Sci. Technol., 1: 133 -140

Ofudje, EA; Awotula, AO; Oladipo, GO; Williams, OD (2014). Detoxifixation of $\mathrm{Cr}$ (vi) ions in $\mathrm{Ag}$ solution via adsorption by raw and activated carbon prepared from sugar-cane waste. Covanant J. Phys. \& Life Sci., 2: $110-122$.

Ofudje, EA; Awotula, AO; Oladipo, GO, Sampson, O; Tella, CA (2016). Removal of hexavalent chromium from aqueous solution by adsorption on Modified groundnut hull. Covenant J. Phys. \& Life Sci., 5: 377 - 388.
Olayinka, OK; Oyedeji, OA; Oyeyiola, OA (2009). Removal of Chromium and Nickel ions from aqueous solution by adsorption on modified Coconut husk. Afr. J. Environ. Sci., 3: 286 - 293.

Rozaini, CA; Jain, K; Tong, KS; Azraa, A (2010). Optimization of Nickel and copper Ions Removal by Modified Mangrove Barks. Intern. J. Chem. Engineering \& Applications, 1: $84-89$

Sathish, T; Vinithkumar, NY; Dharan, G; Kirubagaran, R (2015). Efficacy of mangrove leaf powder for bioremediation of chromium (VI) from aqueous solutions: kinetic and thermodynamic evaluation. Appl. Water Sci., 5: $153-160$.

Stout, MD; Herbert RA; Kissling, GE; Collins, BJ; Travlos, GS; With, KL (2009). Hexavalent Chromium is Carcinogenic to F344/N Rats and B6C3F1 Mice after chronic oral exposure, Environ. Health perspective, 117: 716 - 722.

Timbo, CC; Schulz, MK; Amuanyena, M; Kwaambwa, MH (2007). Adsorptive removal of Chromium (VI) ion from aqueous solution by green Moringa tea leaves biomass. $J$. Encapsulation and Adsorp. Sci., 7: 108 - 117.

Vasqueze, G; Calvo, M; Friere, MSM; GonzalezAlvarez, J; Antorrena, G (2009). Chestnut shell as heavy metal adsorbent: Optimization study of lead, copper and zinc cations removal. $J$. Hazardous Materials, 172: 1402 - 1414. 